\title{
UNIVERSIDADE E EDUCAÇÃO DE JOVENS E ADULTOS: TERRITÓRIO DE VIDAS E CULTURAS
}

\author{
Joana d'Arc de Vasconcelos Neves ${ }^{1}$ \\ Rogério Andrade Maciel $^{2}$ \\ Ana Paula Vieira Souza ${ }^{3}$ \\ Raquel Amorim dos Santos ${ }^{4}$
}

\begin{abstract}
RESUMO
Neste artigo, analisamos as ações desenvolvidas entre a Universidade Federal do Pará (UFPA), Conselho de Juventude e duas escolas que ofertam EJA na rede pública de ensino municipal de Bragança-Pa. Na produção dos dados, consideramos as etapas formuladas do Projeto EJA: Território de Vida e Cultura que compreende: a) diagnóstico da realidade da EJA; b) Realização de oficinas: teatro, pintura em camisas e formação de professores; c) a visão dos alunos e dos professores sobre o projeto. Os resultados apontaram para uma experiência propositiva de reconfiguração da própria modalidade, trazendo para EJA um currículo que envolveu cultura, organização da juventude e formação continuada de professores em um movimento coletivo ressignificando a EJA em territórios de vida e culturas.
\end{abstract}

Palavras-chave: Universidade. Reconfiguração da EJA. Território de vidas e culturas.

\begin{abstract}
In this article, we analyze the actions developed between the Federal University of Pará (UFPA), Youth Council and two schools that offer EJA in the public school system of Bragança-Pa. In the production of the data, we consider the formulated steps of the EJA Project: Territory of Life and Culture which comprises: a) diagnosis of the reality of the EJA; b) Conducting workshops: theater, painting on shirts and teacher training; c) the students 'and teachers' view of the project. The results pointed to a propositive experience of reconfiguration of the modality itself, bringing to EJA a curriculum that involved culture, youth organization and the continued formation of teachers in a collective movement reignifying the EJA in living territories and cultures.
\end{abstract}

Keywords: University. Reconfiguration of EJA. Territory of lives and cultures.

\footnotetext{
${ }^{1}$ Doutor e Mestre em Educação pela Universidade Federal do Pará (UFPA). Professora Adjunta A da UFPA no Campus Universitário de Bragança, Faculdade de Educação. Professora do Programa de Pós-Graduação em Linguagens e Saberes na Amazônia (PPLSA); Linha de Pesquisa: Educação, Cultura e Sociedade. Graduada Plena Pedagogia pela Universidade Federal do Pará (UFPA). Pesquisadora do Grupo de Estudos e Pesquisa Educação de Jovens e Adultos e Diversidade Amazônica (GUEAJA/UFPA). E-mail: jdneves@ufpa.br

${ }^{2}$ Doutorando do Programa de Pós-Graduação em Educação pelo Instituto de Ciências da Educação (UFPA) e Professor Orientador do Curso de Especialização em Educação de Jovens e Adultos na UFPA no Campus de Bragança. E-mail: dancerogerio@yahoo.com.br

${ }^{3}$ Professora da Universidade Federal do Pará - Campus de Bragança. Doutor e Mestre em Educação na Linha de Pesquisa: Políticas Públicas Educacionais pela Universidade Federal do Pará (UFPA). Graduada Plena em Secretariado Executivo Bilíngue (UNAMA). Professora do Programa Linguagens e Saberes da Amazônia (PPLSA) na Linha de Educação. Membro do Grupo de Estudos e Pesquisa Trabalho e Educação (GEPTE/UFPA). E-mail: paulladesa@gmail.com

${ }^{4}$ Doutor e Mestre em Educação pela Universidade Federal do Pará (UFPA). Professora Adjunta A da UFPA no Campus Universitário de Bragança, Faculdade de Educação. Professora do Programa de Pós-Graduação em Linguagens e Saberes na Amazônia (PPLSA); Linha de Pesquisa: Educação, Cultura e Sociedade. Graduada Plena em Pedagogia pela Universidade da Amazônia (UNAMA). Pesquisadora do Núcleo de Estudos e Pesquisa sobre Formação de Professores e Relações Étnico-Raciais (GERA/UFPA). E-mail: rakelamorim@yahoo.com.br
} 


\section{INTRODUÇÃO}

No presente artigo, tivemos como objetivo analisar as ações desenvolvidas entre a Universidade Federal do Pará (UFPA), Conselho de Juventude e duas escolas que ofertam EJA na rede pública de ensino municipal de Bragança-Pa.

As ações educativas do Projeto EJA: Território de Vida e Cultura faz parte de uma experiência desenvolvida pelo Grupo de Estudo e Pesquisa em Educação de Jovens e Adultos e Diversidade na Amazônia (GUEAJA), do Campus Universitário de Bragança, Universidade Federal do Pará, em parceria com duas escolas municipais e com o Conselho da Juventude de Bragança (CONJUVE), com o propósito de estimular o acesso e a permanência dos alunos da EJA.

O citado projeto configura-se como um trabalho coletivo, em que diferentes instituições e sujeitos se propõem a reconfigurar a educação de jovens e adultos, partindo da premissa que a modalidade da EJA, é muito mais do que ensino de escolar, mas como território de vidas e culturas. Nesse sentido, o trabalho coletivo entre CONJUVE, os sujeitos da EJA e a Universidade assumem o compromisso de desenvolver atividades que promovam e compreendam seus sujeitos na totalidade (RELATÓRIO DO PROJETO, 2016, p. 8).

A perspectiva de elaboração desta parceria pedagógica surgiu a partir da preocupação sobre a realidade educacional da população bragantina que apresentava um alto índice de munícipes acima de 15 anos fora da escola, conforme pode ser visualizado nos dados do Instituto Brasileiro de Geografia e Estatística (IBGE), no Quadro 1 a seguir:

Quadro 1 - Indicadores da escolarização da juventude em Bragança.

\begin{tabular}{|c|c|c|c|}
\hline $\begin{array}{c}\text { INDICADOR DE JUVENTUDE } \\
\text { ESCOLARIZAÇÃO }\end{array}$ & $\begin{array}{c}\text { JOVENS DO } \\
\text { CAMPO }\end{array}$ & $\begin{array}{c}\text { JOVENS DA } \\
\text { SEDE }\end{array}$ & $\begin{array}{c}\text { TOTAL DE } \\
\text { JOVENS }\end{array}$ \\
\hline $\begin{array}{c}\text { SEM INSTRUÇÃO OU } \\
\text { COM O PRIMEIRO CICLO } \\
\text { DO FUNDAMENTAL } \\
\text { INCOMPLETO }\end{array}$ & 12.460 & 12.317 & 24.777 \\
\hline $\begin{array}{c}\text { PRIMEIRO CICLO DO } \\
\text { FUNDAMENTAL COMPLETO } \\
\text { OU SEGUNDO CICLO } \\
\text { INCOMPLETO }\end{array}$ & 7.526 & 4.571 & 12.097 \\
\hline $\begin{array}{c}\text { SEGUNDO CICLO } \\
\text { INCOMPLETO OU MAIS }\end{array}$ & 24.338 & 5.230 & 29.568 \\
\hline $\begin{array}{c}\text { ESCOLARIZAÇÃO } \\
\text { INDETERMINADA }\end{array}$ & 6.204 & 3.610 & 9.814 \\
\hline
\end{tabular}




\begin{tabular}{|r|r|r|r|}
\hline TOTAL & 50.528 & 25.528 & 76.256 \\
\hline
\end{tabular}

Fonte: IBGE (2010).

O desafio da expansão do atendimento da EJA no Município de Bragança já não reside apenas em atender a escolarização de sujeitos que jamais foram a escola, mas passou a se estender aqueles que frequentaram o banco escolares, mas neles não obtiveram "sucesso".

Esse desafio não é específico do Município de Bragança, pois, a política pública, para essa modalidade de ensino, vem permitindo que os jovens, com baixa escolaridade, ingressem cada vez mais cedo na EJA, ou seja, 15 anos para o Ensino Fundamental e 18 anos para o Ensino Médio:

Art. 38. Os sistemas de ensino manterão cursos e exames supletivos, que compreenderão a base nacional comum do currículo, habilitando ao prosseguimento de estudos em caráter regular.

$\S 1^{\circ}$ Os exames a que se refere este artigo realizar-se-ão:

I - No nível de conclusão do ensino fundamental, para os maiores de quinze anos;

II - No nível de conclusão do ensino médio, para os maiores de dezoito anos. $\S 2^{\circ}$ Os conhecimentos e habilidades adquiridos pelos educandos por meios informais serão aferidos e reconhecidos mediante exames. (BRASIL, 1996, $\mathrm{s} / \mathrm{p})$.

O referencial teórico adotado foram os estudos de Freire (1987), Arroyo (2001), Santos (2007) que nos ajudaram a analisar a EJA e os processos de exclusão social, política, cultural, econômica e educacional aos quais, os estudantes dessa modalidade de ensino estão submetidos.

Tais explicitações trazem à tona questão problema deste trabalho: é possível dentro da rede e de sistema municipal de ensino pensar outras formas de escola para jovens e adultos? Quais são as implicações que as ações educativas, desenvolvidas no Projeto EJA: Territórios de Vidas e Culturas, trouxeram para alunos e professores da EJA?

Ressaltamos que a produção deste artigo teve como referência o próprio processo de organização e desenvolvimento do projeto, configurando as três etapas: a) diagnóstico da realidade da EJA e da Universidade; b) execução do projeto: aplicação das oficinas; c) a visão de alunos e professores da EJA sobre o projeto;

A escuta sobre o projeto foi realizada com dois alunos e dois professores das escolas da rede municipal de ensino de Bragança que participaram das ações educativas do projeto de intervenção pedagógica na EJA. Para captar a visão desses sujeitos, utilizamos como técnica de coleta de dados a entrevista semiestruturada, "[...] que combina perguntas fechadas (ou 
estruturadas) e abertas, na qual o entrevistado tem a possibilidade de discorrer o tema proposto, sem resposta ou condições prefixadas pelo pesquisador" (MINAYO, 2008, p.108).

Com base no exposto, o artigo está organizado em três partes, além dessa introdução: inicialmente o debate sobre o acesso a realidade da eja e as implicações na política de acesso e permanência do aluno; em seguida, analisamos as ações educativas do projeto de intervenção pedagógica na EJA, em duas escolas públicas do município de Bragança; tecemos as Considerações Finais e por fim Referências, nas quais são informadas as fontes de consulta utilizadas para o aporte teórico desta pesquisa.

\section{A REALIDADE DA EJA E AS IMPLICAÇÕES NA POLÍTICA DE ACESSO E PERMANÊNCIA DO ALUNO E A UNIVERSIDADE}

De acordo com Arroyo (2006), a EJA, em sua história, é muito mais complexa e contraditória do que a história da Educação Básica. Nela se entrelaçam interesses e conflitos, em virtude do público, atendido nessa modalidade de ensino, ser os de jovens e adultos que são trabalhadores, pobres, negros, subempregados, oprimidos, excluídos etc.

A correlação de forças em conflito sobre a realidade social, política, econômica e cultural da EJA, tem condicionado diferentes concepções de educação oferecida a estes sujeitos. Nesse sentido, “[...] os lugares sociais a eles reservados - marginais, oprimidos, excluídos, empregáveis, miseráveis - têm condicionado o lugar reservado a sua educação no conjunto das políticas oficiais" (ARROYO, 2006, p.10).

Daí o perfil das turmas da EJA ser de um público específico, pois geralmente é formada por alunos com defasagem idade-série, advindos de uma trajetória de vida marcada por desistência dos estudos, por sucessivas repetências, pela constituição familiar precoce, pela necessidade de trabalhar, entre outras demandas que impediram a conclusão dos estudos na idade específica (SANTOS, 2007).

Atualmente, existem muitos adultos nas turmas da EJA, entretanto, há uma tendência em aumentar o número de jovens que constituem essas turmas, visto que estes estão migrando do Ensino Fundamental por causa das inúmeras repetências e são removidos com quinze anos de idade para compor as turmas da EJA.

Segundo Brunel (2004, p. 21, grifos da autora), é importante ouvir os jovens excluídos dessa modalidade de ensino, pois, este ouvir é muitas vezes interditado pela escola e até pelos professores, ou seja, “[...] é necessário (re)significarmos o lugar 'simbólico' destes alunos e superarmos o rótulo de fracassados que frequentemente a comunidade escolar os impõe, e retomar com eles sua posição de sujeitos no processo educativo". 
Sobre o contexto em que deve se materializar a EJA, Freire (1997):

[...] uma das tarefas mais importantes da prática educativa-crítica é propiciar as condições em que os educandos em suas relações uns com os outros e todos com o professor ou a professora ensaiam a experiência profunda de assumir-se. Assumir-se como ser social e histórico, como ser pensante, comunicante, transformador, criador, realizador de sonhos, capaz de ter raiva porque é capaz de amar. (FREIRE, 1997, p. 46).

A reflexão de Freire (1997) descreve os problemas relacionados à exclusão escolar que, muitas vezes, são tratados pelos órgãos governamentais como sendo de responsabilidade do próprio aluno, atribuindo, a eles, a culpa por suas dificuldades de aprendizagem e fracasso escolar. Entretanto, isso advém da própria estrutura do sistema capitalista que tem, em sua filosofia, a demarcação da desigualdade social, fator crucial para legitimar que o fracasso, insucesso do aluno da EJA na escola, é assumido por ele quando não demonstra vontade e competência para adquiri-las.

Como nos diz Arroyo (2001), fala-se de aluno evadido e não de aluno excluído. Fala-se de fracasso do aluno e não do fracasso da escola. Há uma responsabilização do fracasso ao próprio educando. Considera-se somente as questões individuais, esquecendo que estas são provocadas por fatores de ordem socioeconômica e culturais que deixam ainda mais evidentes as desigualdades. E nesse contexto afirmamos que esta educação, que defende o individualismo e não o coletivo de experiência do sujeito está a serviço de processos desumanizadores (ARROYO, 2006).

Há de se considerar que na história da educação brasileira, o pensamento pedagógico traz as marcas do paradigma segregador de humano-in-humano, cidadão-sub-cidadão tão presente e persistente no pensamento social, político hegemônico.

Assim, definir um protótipo único, homogenizador de escola, para pensar a EJA, tem servido como parâmetro de segregação dos sujeitos que não conseguem se adequar ao tempo, ao espaço e a organização da escola.

Estamos diante de uma realidade estatística que a oferta da EJA não tem atendido ao número de bragantinos acima de 15 anos que não estão no sistema de ensino e que efetivamente a oferta não tem elevado o nível de escolaridade da população bragantina, dado o nível de evasão e repetência, implicando em novas formas de exclusão social.

Como nos diz Arroyo (2001), a precariedade da realidade social, econômica, afetiva, bem como a história familiar, em que se repete a exclusão social, são as origens da evasão escolar na EJA. Nessa perspectiva, a EJA só se constituirá como um campo do direito na 
medida em que: “[...] o sistema escolar também avançar na sua configuração como campo público de direitos para os setores populares em suas formas concretas de vida e sobrevivência (ARROYO 2001, p. 49).

Nesse sentido, é fundamental que o poder público não ofereça a esses alunos, já marcados pela exclusão, apenas o acesso à educação de jovens e adultos, e sim também meios que possibilitem a vivência em uma escola que se contraponha - como já o fez Paulo Freire (1987), na Pedagogia do Oprimido - ao paradigma que limita o ser humano de ser mais, sujeitos não apenas de educabilidade, humanizáveis pela educação de qualidade, e sim Sujeitos de humanidade, Sujeitos de Pedagogias do Oprimido.

Nessa direção da ruptura de modelos e reconfiguração de um novo paradigma para a Educação de Jovens e Adultos que a Universidade Federal do Pará, por meio do GUEAJA tem, ao longo dos últimos vinte anos, protagonizado, mediante projetos de Ensino, Pesquisa e Extensão, e experiências que a partir de um referencial freireano buscam ver, reconhecer os outros como sujeitos de voz, de saberes, culturas e consciência.

Não se trata da Universidade levar o conhecimento, de levar a conscientização ao oprimido sobre os modelos opressores de fazer a escola, e sim de construir e reconstrui-los com os sujeitos da EJA, visto que "[...] os próprios oprimidos preparados para entender os significados de uma sociedade opressora, de um Estado opressor, porque ninguém melhor que eles sente os efeitos da opressão" (ARROYO, 2018, p. 15).

\section{EJA: TERRITÓRIOS DE VIDAS E CULTURAS}

É preciso destacar que a EJA se encontra diante de antigos e novos desafios para não desumanizar os sujeitos que dela buscam oportunidade de educarem-se. As políticas públicas, voltadas para essa modalidade de ensino, garantem o acesso, mas quem garante a qualidade social? Se não houver qualidade, a evasão será a consequência e, mais uma vez, a exclusão desse aluno da EJA será inevitável (ARROYO, 2001).

Para tanto, integramos ações educativas alinhadas à realidade dos alunos - o teatro do oprimido e a oficina de pintura, e dos professores - formação sobre a práxis didáticopedagógico na EJA e sua relação com a EJA enquanto Território de vida e culturas. Trata-se de uma experiência que busca ser forjada com os sujeitos do processo, enquanto sujeitos de vidas e culturas que lutam pela recuperação de sua condição de ser mais. Subdividida nas seguintes etapas: Diagnóstico; Oficinas; Formação de Professores. 


\subsection{DIAGNÓSTICO DA REALIDADE: O PONTO DE PARTIDA PARA ELABORAÇÃO DO PROJETO}

O diagnóstico da realidade partiu do planejamento entre Grupo de Estudo e Pesquisa em Educação de Jovens e Adultos e Diversidade na Amazônia (GUEAJA), da Universidade Federal do Pará, Campus Universitário de Bragança e duas escolas da EJA, visando mapear a realidade da EJA no Município de Bragança. De acordo com o diagnóstico, identificamos que os alunos da EJA estavam imbricados por processo de exclusão. Entre eles, destacavamse:

a) a não participação dos alunos da EJA nos espaços educativos escolares;

b) a falta de política de valorização dos sujeitos (professores/alunos) dessa modalidade de ensino;

c) a falta de formação continuada para esta modalidade ensino;

d) a falta de um currículo específico;

e) a falta de associação dos conteúdos escolares à realidade, saberes e cultura dos alunos. (RELATÓRIO DO PROJETO, 2016, p. 2).

Os dados supracitados deram a base empírica para elaborar do Projeto EJA: Territórios de Vidas e Culturas, com mediação dos seguintes objetivos:

1) Implantar a campanha junto a coordenações pedagógicas das escolas que possuem essa modalidade da Educação Básica para garantir aos alunos da EJA uso dos espaços e atividades pedagógicas na escola e demais espaços na escola;

2) Criar parcerias com diferentes instituições para discutir e vivenciar projetos voltados para a permanência dos alunos da EJA junto na rede municipal de ensino

3) Fortalecer a parceira UFPA e escolas municipais da EJA no sentido de para ampliar a política de formação continuada dos professores que atuam na EJA no município. (RELATÓRIO DO PROJETO, 2016, p. 06).

Assim, para a implementação dessa proposta foi fundamental para o estabelecimento de parcerias que deram agilidade e vigor às ações educativas direcionadas para qualidade social da EJA, bem como o fortalecimento do trabalho docente, tendo em vista o salto qualitativo no desenvolvimento no processo de escolarização de qualidade socialmente referenciada.

O Projeto EJA: Território de Vida e Culturas tem como pressuposto de que é importante que os jovens e adultos adquiram uma visão de mundo mais consistente, uma percepção mais clara da sua realidade, enquanto sujeitos excluídos dos seus direitos, dos bens culturais e materiais produzidos pela sociedade capitalista, para que possam refletir e intervir na realidade em que estão inseridos de forma crítica e autônoma (RELATÓRIO PROJETO, 2016). 
Quadro 03 - Ações Educativas e objetivos do projeto de intervenção pedagógica.

\begin{tabular}{|c|l|}
\hline AÇÃO & \multicolumn{1}{|c|}{ OBJETIVOS } \\
\hline $\begin{array}{c}\text { Oficina de arte } \\
\text { dramática. }\end{array}$ & $\begin{array}{l}\text { Visa estimular o teatro do oprimido que utiliza a educação popular, } \\
\text { difundida pelo teatrólogo Augusto Bual. }\end{array}$ \\
\hline $\begin{array}{c}\text { Oficina de } \\
\text { Pintura }\end{array}$ & $\begin{array}{l}\text { Desenvolver técnicas de pintura com técnica stêncio - uso de } \\
\text { diversos materiais blocados, utilizados para pintura de tecidos, } \\
\text { madeira, cerâmica e paredes. }\end{array}$ \\
\hline
\end{tabular}

Fonte: Relatório do projeto de acesso permanência (2016, p. 10).

\subsection{OFICINAS}

O teatro do oprimido é um método estético que sistematiza exercícios, jogos e técnicas teatrais que objetivam a desmecanização física e intelectual de seus praticantes, e a democratização do teatro. Esse teatro foi iniciado nos anos 70, criado pelo teatrólogo Augusto Boal.

Atualmente, o teatro do oprimido é desenvolvido nas ruas, escolas, igrejas, sindicatos, teatros regulares, prisões, com a finalidade política da conscientização. É uma técnica em que o teatro se torna o veículo para a organização, debate dos problemas, além de possibilitar, a formação de sujeitos sociais que possam fazer-se veículo multiplicador da defesa por direitos e cidadania para a comunidade.

O teatro é o ato de criar, de fazer o agir se transformar na realidade. E ao transformar a realidade, 'sofre' a inferência do sujeito. Isso são dois pilares primordiais para a sua existência: a valorização do ser humano e o reconhecimento de suas potencialidades como sujeito de transformação social. Ele permite que a ação política seja, no fundo, uma ação cultural para a liberdade feita com eles e por eles, tal como ressalta Freire (1987). Nessa ação cultural, cada um assume uma função específica e, ao final, todos assumem o que hoje chamamos de protagonismo social.

A outra ação educativa desenvolvida com os alunos da EJA foi a oficina de pintura com técnica de Estêncil. A oficina contou com a participação dos integrantes do CONJUVE, onde se discutiu o conceito da pintura mediando à técnica de Estêncil e a metodologia usada para realizar o trabalho. Daí foram planejadas as peças que seriam construídas.

O Estêncil é uma técnica de pintura em que é aplicada em áreas vazadas de um molde que dá forma ao desenho que se deseja estampar superfície lisa, como: tecidos, papel, paredes, madeira, cerâmica e paredes. Esses moldes podem ser feitos de diversos materiais, como: acetato, radiografias antigas, cartões plásticos ou metal. 
Com os professores da EJA, os pesquisadores do GUEAJA realizaram a formação permanente sobre a práxis didático-pedagógico na EJA e sua relação com a política de acesso e qualidade social da educação para jovens e adultos na escola pública.

Para Freire (1997, p. 58), formação permanente é uma conquista da maturidade, da consciência do ser. Em suas palavras "ninguém nasce educador ou marcado para ser educador. A gente se faz educador, a gente se forma, como educador, permanentemente, na prática e na reflexão da prática". Nesse sentido, essa premissa teórica fundamentou as ações educativas com professores e alunos da EJA, durante a realização do projeto em foco.

A vivência do projeto perpassa pelos desdobramentos de uma política de acesso e permanência para e com a educação de jovens e adultos nas duas escolas selecionadas. Para tanto, o projeto integralizou-se em por três momentos que ocorriam simultaneamente: a realização do teatro do oprimido; a oficina de pintura com técnica de Estêncil e as palestras com os professores.

\subsection{O TEATRO DO OPRIMIDO}

A realização do teatro se constitui em um movimento de conquista da confiança do aluno da EJA, que historicamente foi excluído do processo de apropriação dos bens culturais e materiais da sociedade. Nesse sentido, é que a participação dos alunos na oficina do teatro do oprimido se constituiu no momento de expressão corporal do diálogo crítico.

O teatro do oprimido possibilita uma "descoberta" de nossas potencialidades colocandonos diante de nós mesmos e de nossas próprias resistências, reconhecendo que nos foram impostas formas de pensar, sentir e agir que subestimam o conhecimento construído ao longo de nossa história (SOUSA, 2007).

Inicialmente, durante a realização do teatro de oprimido, os alunos ficaram tímidos, inibidos e com vergonha, mas posteriormente foram se expressando de forma mais dinâmica e participativa. A partir da participação dos alunos na oficina foram feitas reflexões críticas sobre o que estes pensam sobre as aulas, os conteúdos de ensino, o processo de ensino e a aprendizagem. Logo, essa base só pode ser concretizada pelo diálogo.

O diálogo é o "encontro amoroso dos homens que, mediatizados pelo mundo, o pronunciam e o transformam e, assim fazendo se humanizam no mundo para a humanização de todos" (FREIRE, 2002, p.43). Segundo essa concepção, o diálogo inclui, além da dimensão ética do encontro amoroso dos homens, o objeto do conhecimento - o mundo - que desafia e mediatiza a relação interpessoal e comunicativa. 
O segundo momento se constituiu na produção coletiva do texto a partir da realidade social dos alunos. Para tanto, houve a escolha da temática de interpretação, a construção do roteiro da peça, a escolha das personagens e construções das falas.

Figura 1: Produção coletiva do roteiro das falas para o teatro advindo da realidade dos alunos.

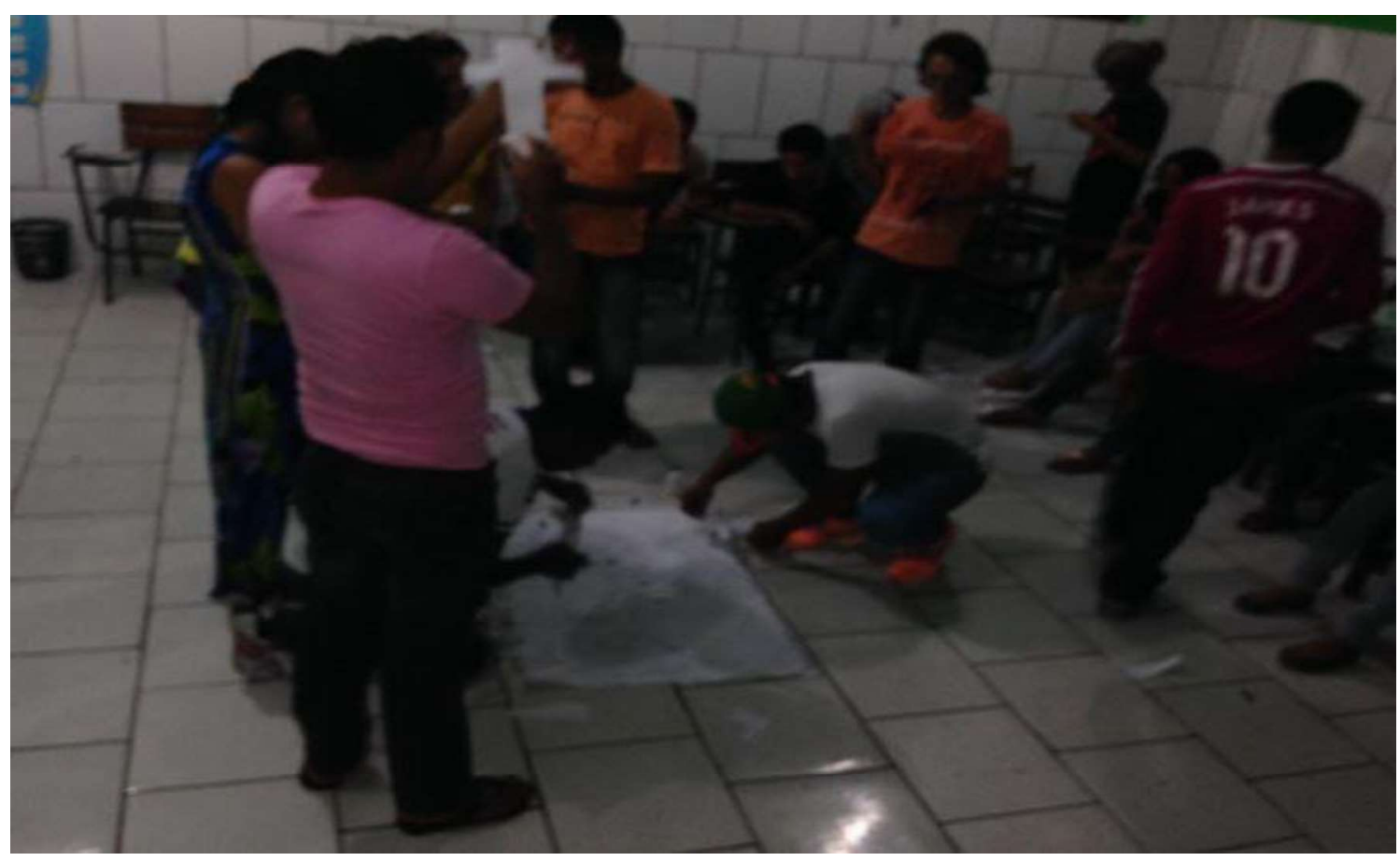

Fonte: Acervo fotográfico dos pesquisadores, 2016.

De acordo com Freire (2002), as relações do homem com a realidade são resultantes dos atos de criação, recriação e decisão, que este vai dinamizando no seu mundo social. Nesse processo, o homem percebe as contradições da sua vida, principalmente quando reflete sobre a sua inserção no mundo. É com essa compreensão que o teatro do oprimido possibilitou a reflexão crítica acerca das condições objetivas de vida dos sujeitos que, muitas vezes, nem a escola possibilita esta reflexão. Em síntese é a arte-educação, integrando as diversas linguagens artísticas aos princípios da Educação Popular, em um processo social e histórico.

Os alunos da EJA, ao participarem do teatro do oprimido, desenvolveram uma tomada de consciência, mediante a integração ativa no processo de interpretação do mundo mediatizado pela esperança, pelo sonho, pela utopia, como aponta Freire (2002, p.25), “[...] sonhos e esperanças construído em uma participação ativa, por meio de propostas de atuações que defrontem os acontecimentos históricos - não só pelo fato de indignação, mas para a própria compreensão do contexto histórico-social". 


\subsection{A OFICINA PINTURA COM TÉCNICA DE ESTÊNCIL}

A oficina de pintura com técnica de Estêncil foi desenvolvida pelos integrantes da CONJUVE com a participação dos alunos da EJA. Para isso, foram ensinados os seguintes procedimentos, para a materialização da pintura:

a) usar acetato ou radiografia antiga;

b) prenda o estêncil com pedaços de fita crepe, se a pintura for feita com aerógrafo, escolher de preferência um pincel redondo, do tipo brocha;

c) usar pouca tinta para o estêncil não vazar, se necessário remover antes o excesso de tinta na brocha com um pedaço de papel à parte; e

d) pintar sempre de fora para dentro dando batidinhas, como se pintasse como uma esponja que, aliás, pode ser usada para pintar.

Esses materiais possibilitaram a seguinte produção artística:

Figura 2: Pintura dos alunos da EJA, utilizando a técnica de stêncil.

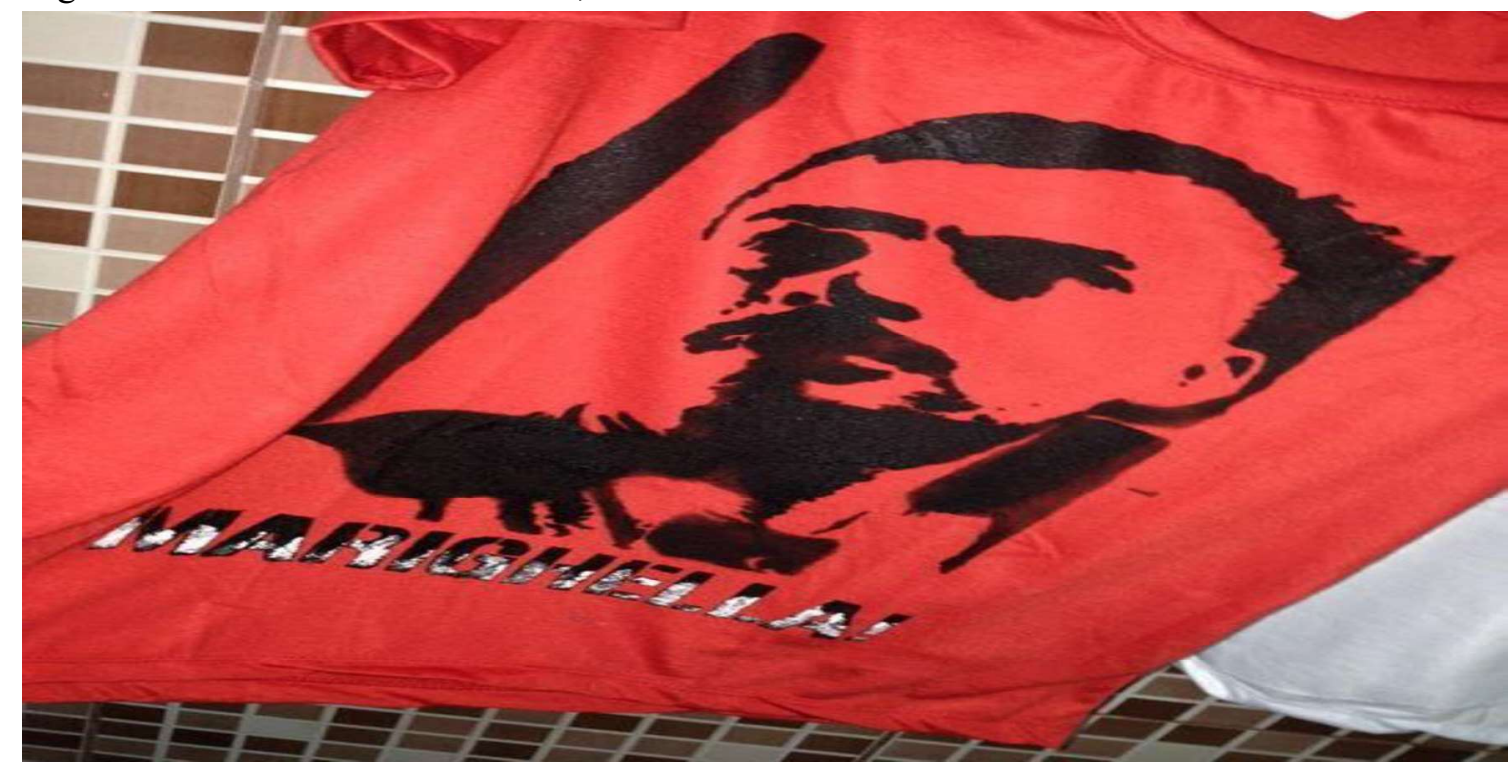

Fonte: Acervo fotográfico dos pesquisadores, 2016.

A oficina de pintura com a técnica de estêncil foi à base para desenvolver à criatividade, a interação e a produção artística dos alunos da EJA. Isso significa dizer que nas oficinas de pintura foi potencializado o máximo de criatividade dos alunos da EJA, em que surgiram pinturas inéditas e que refletiam a realidade social dos alunos. 


\section{FORMAÇÃO DE PROFESSORES: A PRÁXIS DIDÁTICO-PEDAGÓGICO NA EJA E SUA RELAÇÃO COM A POLÍTICA DE ACESSO E PERMANÊNCIA DE JOVENS E ADULTOS}

A práxis didático-pedagógico na EJA é, acima de tudo, um desafio, pois o educador consciente passa grande parte do seu tempo questionando-se, revendo conceitos, buscando dar o melhor a seus educandos. Ser professor significa contribuir para a formação humana dos sujeitos históricos.

Ser professor da EJA é ensinar o aluno a aprender e participar de decisões que envolvam o projeto da escola, lutar contra a exclusão social, relacionar-se com os alunos, com os colegas da instituição e com a comunidade do entorno desse espaço (ARROYO, 2001).

Dessa forma, faz-se necessário uma qualificação dos profissionais envolvidos neste processo. É fundamental que a equipe docente esteja bem preparada, por este motivo é extremamente importante uma formação continuada, em que todos tenham a oportunidade de repensar a sua práxis didático-pedagógica. Pois, a formação continuada é uma realidade possível para a melhoria da qualidade do ensino e da aprendizagem dos sujeitos da EJA, no contexto educacional contemporâneo.

Por isso, foi desenvolvida uma palestra para docentes, tendo como objetivo levar os educadores refletirem a sua prática docente e de vida. Para tanto, apoiados em Freire (2006, p. 32, grifos do autor) quando explica que "[...] quanto mais alguém, por meio da ação e da reflexão, se aproxima da 'razão', dos 'logos', da realidade objetiva e desafiadora, tanto mais introduzindo-se nela, mas alcançara o seu desvelamento". Esse desvelamento possibilita a reflexão sobre a prática do cotidiano e sua relação com a teoria.

A formação de professores, nas duas escolas em que foi desenvolvida a intervenção pedagógica, iniciou-se com os trechos do filme Escritores da Liberdade, a fim de refletir quem são os alunos da EJA. As fotos, a seguir, demonstram os momentos da formação com os professores da EJA: 
Figura 3 e 4 - Formação com os professores da EJA.
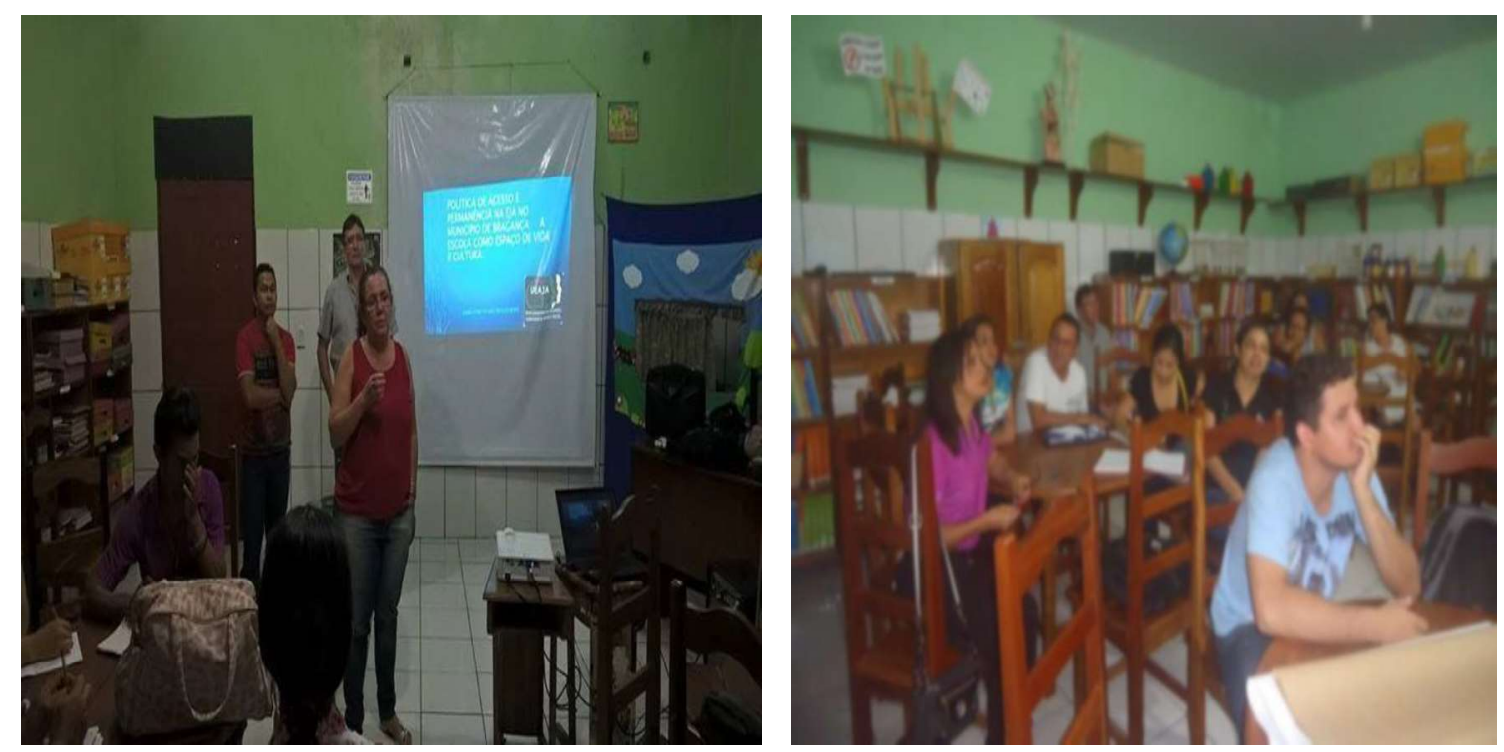

Fonte: Acervo fotográfico dos pesquisadores, 2016.

O processo de reflexão, realizado nas palestras, possibilitou aos professores refletirem sobre a sua práxis didático-pedagógico, visto que, uma educação que se preocupa com os seus sujeitos, precisa voltar sua atenção para a necessidade de rever a organização da escola, como nos diz Freire (2009, p.151), “[...] os homens se libertam em comunhão, não há outra forma de transformação de sua prática que sua contribuição, ao discutir, ao opinar, questionar sua realidade, para então, modificá-la, exercendo assim, seu papel de sujeito de transformação".

A partir dessa reflexão foi proposto que os professores participantes refletissem sobre:

a) a escola que temos e a que queremos;

b) o que há de ruim e como surgiram esses problemas, quais suas causas e suas histórias; e

c) pensar sobre qual escola e que alunos da EJA queremos e quais os caminhos/ações podemos tomar, pensando também nos sujeitos e nos papéis individuais e coletivamente.

Podemos inferir que os professores da EJA nas Escolas Cristiano Rosa e Theodomira Lima estão em busca de um novo significado para EJA. Na construção desse novo significado, alguns princípios estão claros para esses professores:

a) que ela precisa reconstruir novas possibilidades escolares, não vividas anteriormente;

b) que seja produtora de novas identidades;

c) que haja oportunidades diferenciadas para que os alunos tenham condições de estabelecer novas redes de conhecimentos; e

d) que oportunize novas construções. 
Tais elementos supracitados possibilitam a compreensão da práxis didático-pedagógico na EJA e sua relação com a política de acesso e permanência de jovens e adultos na Escola Pública, tendo em vista que Freire (1987) adverte que o ser humano é um ser incompleto e em formação constante. Nesse sentido, os educadores evidenciam que os alunos da EJA têm características próprias e marcantes, visto que as práticas de ensino, nessa modalidade, precisam ser transformadas no sentido de levar o professor a criar no (a) aluno (a) o desejo de inquietude, de não se deixar moldar, negativamente, diante das adversidades cotidianas.

\section{A VISÃO DE ALUNOS E PROFESSORES SOBRE O PROJETO EJA: TERRITÓRIO DE VIDA E CULTURA}

Os professores que participaram da palestra relataram que esta trouxe um impacto significativo na medida em que permitiu a (re)organização do trabalho pedagógico na escola; mas, principalmente, por ter vindo atender ao anseio dos professores da EJA para essa formação continuada, como podemos observar nos excertos a seguir:

[...] A formação dos professores possibilitou uma nova perspectiva de organização do trabalho pedagógico. (PROF. EJA -1).

[...] Veio ao encontro dos anseios dos professores, já que a muito tempo não havia esse olha diferenciado que ocorre hoje, com a modalidade da EJA. Isso nunca aconteceu na EJA, eu já atuo a muito tempo na EJA e esse movimento que temos hoje, nunca ocorreu antes em Bragança. (PROF. EJA - 2).

[...] Veio ao anseio do que justamente precisamos para desenvolver um bom trabalho, pois os professores também precisam ressignificar o seu trabalho. E esse movimento que está ocorrendo na EJA é muito significativo. (PROF. EJA - 3).

A formação de professores na escola atendeu os anseios dos professores que passam a ressignificar a sua prática educativa com os alunos da EJA. E isso é significativo para e com os professores dessa modalidade de ensino, uma vez que possibilitam aos docentes sob uma nova perspectiva de organização do trabalho pedagógico.

É preciso discernir que os professores da EJA identificam os alunos como sujeitos de desejos, problemas, carências e deficiências no desenvolvimento do ensino. Logo, a realidade social dos alunos é o principal critério para o ressignificar a práxis didático-pedagógico (FREIRE, 1987).

Do ponto de vista dos elementos inovadores que o projeto possibilitou ao que concerne a qualificar o trabalho pedagógico docente na EJA, verificamos que este tinha três 
características: novas ações pedagógicas, novas ideias e a possibilidade do trabalho interdisciplinar.

[...] Possibilitou novas ações pedagógicas, apesar do professor de hora/aula tenham alguma dificuldade de efetivar a proposta. (PROF. EJA -1).

[...] Trouxe novas ideias, deixou algo novo, a EJA mudou, houve uma juvenização e a escola continua a mesma, e essa formação vem trazendo umas propostas de interdisciplinaridade, que há muito ansiavam. (PROF. EJA - 3).

[...] É algo inovador que tem ocorrido na EJA, e que não deve parar, vejo que se colocado em prática o que desenvolvemos nas formações só temos a evoluir como trabalho pedagógico. (PROF. EJA - 2).

Para Arroyo (2001), toda intervenção pedagógica na escola é uma fase de superação das adversidades encontradas nessa instituição. E isso está imbricado pelo processo de formação de professores na escola que os faz refletir sobre a responsabilidade do educador na preparação do material para o aprendizado do aluno. Porém, quando se fala em material, quase nunca se imagina que a preparação do próprio educador é uma prática inerente a esse conceito, pois a ele está afeta a responsabilidade de formar. E isso corresponde a proporcionar ao indivíduo a capacidade de distinguir entre o que lhe é posto à frente e aquilo que, de fato, lhe interessa. É a reflexão da própria prática e planejamento coletivo.

Esse planejamento coletivo, movimentado pelo projeto de intervenção, viabiliza a integração de novas formas de organização do trabalho pedagógico, mas é preciso não desconsiderar a realidade que está inserida na EJA, pois, apesar de difícil organização do professor hora/aula.

[...] Apesar da dificuldade citada anteriormente, vejo que a proposta é muito boa, pois, os professores terminam de forma muito individualizada desenvolver suas ações. (PROF. EJA -1).

Santos (2007) menciona que o planejamento coletivo pode favorecer uma melhor leitura e interpretação das experiências pedagógicas, mas isso depende que haja relações de confiança que pressuponham ligações de amizade ou a sensação de fazer parte integrante de uma equipe pedagógica. No caso do projeto de intervenção pedagógica de acesso e permanência, este permitiu a escola e aos professores identificarem que a forma de organização e ações dos professores são muito isoladas. Além do que, não se pode desconsiderar que, geralmente, o professor da EJA fala sobre o valor do projeto e a rotatividade dos professores para desenvolver este projeto:

[...] É uma proposta inovadora, com embasamento teórico, o que possibilitará o desenvolvimento de um excelente trabalho, que se busque 
desde do início do ano, mas um fator limitador é a rotatividade de professores, em dezembro os temporários são desligados e muitos não voltam, essa rotatividade inviabiliza uma continuidade. (PROF. EJA - 3).

Arroyo (2001), nos diz que a ideia de pertencimento do professor da EJA ao desenvolver um trabalho significativo com os alunos, seja por pesquisa, projeto, e comunidade escolar, está correlacionado com a forma de organização, turmas, horários, espaços, que são gerenciados pelas secretarias municipais e estaduais do Brasil, pois o tempo e espaço na escola possibilita os estreitamentos entre o docente e o aluno, facilitando a busca de um trabalho sistematizado com esses jovens. No caso do município de Bragança, esse estreitamento aconteceu pela mediação do projeto de intervenção, mas é preciso considerar que o tempo e espaço dos professores temporários que são desligados do seu trabalho, a rotatividade, rompe com os trabalhos que foram planejados no início do ano letivo.

Ao que se refere à visão dos alunos, estes visualizam o projeto de intervenção da seguinte maneira:

[...] Achei um bom incentivo, uma oportunidade muito boa aprendeu coisas novas (ALUNO EJA - 1).

[...] Foi muito bom, interessante, coisa que não sabia eu aprendi, não sabia que se pintava camisas desse jeito, por exemplo. (ALUNA EJA -2).

Nessas falas, verificamos que os alunos atribuem sua importância com relação ao projeto que trouxe inúmeras oportunidades de conhecimentos durante o processo de oficinas do teatro e pintura. Isso contribuiu para a importância dos alunos na escola, pois:

[...] A nova experiência me incentivou a continuar os estudos e me formar. (ALUNO EJA - 1).

[...] A gente aprende coisa diferente, incentiva a gente a continuar os estudos, se formar, eu parei um tempo, mas. Agora não paro mais! (ALUNO EJA - 1).

[...] Aprendi até uma forma de ganhar um dinheiro com a pintura de camisas, aprendi na oficina de estêncil. (ALUNA EJA - 2).

Essa experiência permitiu aos alunos um caráter de estímulo para que estes continuarem a estudar, bem como os incentivou a continuarem os seus estudos na escola.

Ao que se refere ao ponto de vista dos alunos, eles caracterizaram que as oficinas devem continuar mostrando as diversas formas de aprender, distanciando-se de modelos que priorizam as aulas só por metodologias de escritas. Isso é perceptível na fala dos alunos: 
[...] Foi muito boa, acho que deviria continuar. (ALUNO EJA - 1).

[...] Na sala de aula é só escrever, escrever. Nas oficinas "incentivou" melhor. Me incentivou muito mesmo continuar, oficina de artesanato também seria bom. (ALUNA EJA - 2).

O Projeto EJA: Território de Vidas e Culturas possibilitou o incentivo e estímulo para continuarem o seu estudo na escola. Tanto é que se propuseram a continuar com novas ações educativas:

[...] Gostaria de ter oficinas de reciclagem, trabalhos com garrafas pet e outros materiais. (ALUNO EJA - 1).

[...] Acho que foi muito bom, gostaria que continuasse o teatro, pois, desenvolve muito as pessoas, elas ficam mais descontraídas. (ALUNA EJA $-1)$.

A proposição dos alunos sobre novas ações educativas no EJA: Território de Vidas $e$ Cultura foram relevantes para a estimular os alunos tanto na escola quanto na participação social. Isso possibilitou, também, a inserção deles para o processo de escolhas sobre outras ações que podem ser inseridas no projeto de intervenção para o ano de 2016.

Observamos que o projeto de intervenção e suas ações, desenvolvidas para e com os alunos da EJA, foi um projeto somente em duas escolas da rede municipal de ensino. Esse projeto precisa ser redimensionado para a rede municipal no sentido de incentivar a continuação dos alunos da EJA na escola.

\section{CONSIDERAÇÕES FINAIS}

O Projeto EJA: Território de Vidas e Cultura, desenvolvido pelo Grupo de Estudo e Pesquisa em Educação de Jovens e Adultos e Diversidade na Amazônia (GUEAJA), da Universidade Federal do Pará, Campus Universitário de Bragança em escolas da rede de ensino municipal contribuiu de maneira significativa para a aproximação dos professores, coordenadores da EJA, alunos e comunidade escolar.

Este Projeto EJA: Território de Vidas e Cultura, pensando no público alvo alunos da EJA foi materializado numa organização que perpassou pela atividade diagnóstica, elaboração de atividades pelo teatro do oprimido, oficina de pintura e a formação de professores.

Após a atividade diagnóstica no Município e a escolha das duas escolas que apresentam um elevado índice de evasão, uma das primeiras ações que foi elaborada para estreitar os laços entre a os alunos da escola e a coordenação da EJA foi a operacionalização do teatro do oprimido e em seguida a oficina de pintura, posteriormente a isto, pensando na mudança 
didática e pedagógica dos professores para refletir sobre a sua práxis docente, foi construído uma capacitação dos professores para contribuir nas suas didáticas para e com os alunos da EJA.

Apesar de a rede municipal disponibilizar o acesso, via abertura de matriculas nas escolas, concluímos ser um desafio para o sistema educacional do município, motivar que os alunos evadidos retornem aos estudos e vejam a aprendizagem como algo significativo para suas vidas.

As ações do Projeto EJA: Território de Vidas e Cultura, até mesmo pelas considerações de alunos e professores, alcançaram os objetivos de desenvolver suas propostas educativas inovadoras que estimulam a permanência com qualidade social dos alunos na EJA nas duas escolas municipais.

Isso se configurou como o grande desafio desse projeto, o reconhecimento de que as práticas sociais cotidianas se constituem como conhecimentos que precisam ser reconhecidos pelos educadores como válidos e como subsídios primários para a construção do currículo escolar freireano que, potencializados pela participação ativa dos sujeitos, por intermédio dos diálogos, possibilita a ressignificação do conhecimento do senso comum em conceitos científicos articulados a redes de saberes já existentes, contribuindo para que se tornem mais densos e diversificados.

\section{REFERÊNCIAS}

ARROYO, M. G. Educação de jovens e adultos: um campo de direitos e de responsabilidade pública. In: SOARES, L.; GIOVANETTI, M. A.; GOMES, N. L. (org.). Diálogos na educação de jovens e adultos. Belo Horizonte: Autêntica, 2001. p. 19-50.

ARROYO, M. G. A educação de jovens e adultos em tempos de exclusão. In: BRASIL. Ministério da Educação. Construção coletiva: contribuições à educação de jovens e adultos. Brasília: UNESCO/MEC/RAAAB, 2006. p. 221- 230.

ARROYO, M. G PAULO FREIRE: UM OUTRO PARADIGMA PEDAGÓGICO? 2018 Disponível em: http://appsindicato.org.br/wp-content/uploads/2018/08/Arroyo-PAULOFREIRE-UM-OUTRO-PARADIGMA-PEDAGOGICO.pdf Acesso em 10.12.2018

BRASIL. Lei $n^{0}$ 9.394, de 20 de dezembro de 1996. Estabelece as diretrizes e bases da educação nacional. Brasília, DF, Presidência da República. Disponível em: https://www2.camara.leg.br/legin/fed/lei/1996/lei-9394-20-dezembro-1996-362578publicacaooriginal-1-pl.html. Acesso em: 14 fev. 2018.

BRUNEL, C. Jovens cada vez mais jovens na educação de jovens e adultos. Porto Alegre: Mediação, 2004. 
FREIRE, Paulo. Pedagogia do oprimido. Rio de Janeiro: Paz e Terra, 1987

FREIRE, Paulo. Professora sim, tia não: cartas a quem ousa ensinar. São Paulo: Olho D’Água, 1997.

FREIRE, Paulo. Ação cultural para a liberdade e outros escritos. 10. ed. São Paulo: Paz e Terra. 2002.

FREIRE, Paulo. Pedagogia da esperança: um reencontro com a Pedagogia do oprimido. São Paulo: Paz e Terra, 2006.

FREIRE, Paulo. Pedagogia da solidariedade. São Paulo: Villa das Letras Editora, 2009

MINAYO, Maria Cecilia de Souza. O desafio do conhecimento. 11 ed. São Paulo: Hucitecm 2008.

SANTOS, Wildson Luiz Pereira dos. Educação científica na perspectiva de letramento como prática social: funções, princípios e desafios. Revista Brasileira de Educação, Rio de Janeiro, v. 12, n. 36, p. 474-492, 2007.

SOUSA, Vera Solange Pires Gomes de. Entre cenas, enredos e roteiros: A formação humana pela via da criação artística a experiência do grupo de teatro da UNIPOP. 2007. Dissertação do Programa de Pós-Graduação em Educação da Universidade Federal do Pará. Belém-Pa.

\section{Fontes Documentais}

RELATÓRIO DO PROJETO EJA: Território de vidas. Bragança: UFPA, 2016.

Recebido em 25.02.2019

Aprovado em 24.03.2019 